\title{
Pengaturan Pelepasan Obat dari Tablet dengan Sistem Matriks Karagenan
}

\author{
Wedi Akbari, Anis Yohana C., Marline Abdassah \\ Program Studi Magister Farmasi, Fakultas Farmasi, Universitas Padjadjaran \\ JI. Raya Bandung Sumedang km 21 Jatinangor 45363 \\ *E-mail: wediakbari53@gmail.com \\ (Submit 28/2/2020, Revisi 21/3/2020, Diterima 11/4/2020)
}

\begin{abstract}
Abstrak
Sistem matriks merupakan sistem pengaturan pelepasan obat dari tablet yang populer. Matriks tablet yang umum digunakan adalah golongan eter selulosa seperti hidroksi propil metil selulosa (HPMC), hidroksi propil selulosa (HPC) dan natrium karboksi metil selulosa ( $\mathrm{Na} \mathrm{CMC}$ ). Golongan eter selulosa sintetik ini banyak digunakan karena memiliki sifat mengembang dan kompresibilitas yang baik. Polimer alam seperti karagenan telah banyak diteliti sebagai komponen penyusun matriks tablet untuk memperoleh pengaturan pelepasan obat dari matriks yang efektif. Karagenan dapat digunakan sebagai penyusun matriks mengingat polimer tersebut memiliki berat molekul yang besar dan mempunyai viskositas dan kemampuan membentuk gel yang tinggi. Dalam upaya pengembangan sistem matriks tablet dari bahan karagenan diperlukan pengetahuan yang baik mengenai karakteristik fisika kimia dari karagenan dan obat yang digunakan.
\end{abstract}

Kata kunci : sistem matriks, karagenan, pembentukan gel.

\section{Outline}

- Pendahuluan

- Karagenan

- Sistem matriks

- Pengaturan Pelepasan Obat dari Matriks Karagenan

- Kesimpulan

- Daftar Pustaka

\section{Pendahuluan}

Karagenan merupakan polisakarida alami yang berasal dari spesies tertentu rumput laut merah (Rhodophyta). Karagenan pertama kali diekstrak pada tahun 1837 dan telah lama digunakan sebagai komponen pembentuk gel, peningkat viskositas dan peningkat kestabilan pada industri pengolahan makanan ${ }^{1}$. 
Ada tiga tipe utama karagenan yang sering digunakan pada industri makanan yaitu tipe K- (kappa), I- (iota), dan $\lambda$ - (lamda). Tipe $\lambda$ - (lamda) merupakan larutan yang kental tetapi tidak membentuk gel sedangkan tipe $\mathrm{K}$ - (kappa) dan I- (iota) tidak larut dalam air tetapi membentuk gel².

Seiring dengan berkembangnya penelitian dalam dua dekade terakhir, karagenan semakin banyak digunakan sebagai biomaterial untuk berbagai tujuan farmasetik ${ }^{3,4}$. Penggunaan karagenan dalam berbagai aplikasi biomedis dapat memperbaiki formulasi dan mengatur pelepasan obat ${ }^{5}$.

Pada sediaan tablet, pengaturan pelepasan obat antara lain dapat dikendalikan dengan sistem matriks. Matriks tablet dari golongan eter selulosa banyak digunakan karena memiliki sifat mengembang dan kompresibilitas yang baik. Beberapa polimer alam seperti karagenan, xanthan dan guar gum juga telah banyak diteliti sebagai komponen penyusun matriks tablet untuk memperoleh kontrol pelepasan obat dari matriks yang efektif ${ }^{4}$.

\section{Karagenan}

Karagenan terdiri dari rantai linear panjang D-galaktosa dan D-anhidrogalaktosa dengan sulfat ester, dan karena itu bersifat anionik. Gugus sulfat biasanya dinetralkan oleh kation, seperti $\mathrm{Na}^{+}, \mathrm{K}^{+}$dan $\mathrm{Ca} 2{ }^{+} 6$. Massa molekul rata-rata karagenan di atas $100 \mathrm{kDa}$, dengan kandungan ester-sulfat antara $15-40 \%{ }^{7}$. Karagenan telah tercantum dalam USP 35- NF30 S1, BP 2012 dan EP $7.0^{8}$.

\section{Struktur Kimia}

Tiga varietas utama karagenan adalah k- (kappa), ।- (iota), dan $\lambda$ - (lamda) ( Gambar $1)^{1}$. $\mathrm{k}$ - karagenan hanya mempunyai satu gugus sulfat untuk setiap pengulangan unit disakarida sedangkan - karagenan mempunyai dua dan $\lambda$ - karagenan mempunyai tiga gugus sulfat untuk setiap pengulangan unit disakarida. Hal ini mengakibatkan tiga varietas karagenan tersebut memiliki perbedaan densitas muatan yang linier $(\lambda>1>$ $\mathrm{K})^{9}$ dan kelarutan $(\lambda>\mathrm{I}>\mathrm{K})^{6}$. $\mathrm{K}$ - karagenan hanya larut dalam air panas, sementara Ikaragenan dan $\lambda$-karagenan larut dalam air dingin dan panas ${ }^{6,7}$. Kation tertentu seperti $\mathrm{Na}^{+}, \mathrm{K}^{+}, \mathrm{Ca}^{2+}$ dan $\mathrm{Mg}^{2+}$, dapat mempengaruhi kelarutan karagenan ${ }^{10}$. Pada $\mathrm{K}-$ karagenan dan I -karagenan terdapat jembatan 3,6-anhydro sedangkan pada $\lambda$ karagenan tidak ada ${ }^{1}$.

\section{Pembentukan Gel}

Pembentukan gel adalah adalah sifat kunci yang dimiliki $\mathrm{K}$ - karagenan dan $\mathrm{I}-$ karagenan. Diduga faktor kunci terjadinya gelasi pada $\mathrm{K}$ - karagenan dan I-karagenan adalah karena adanya jembatan 3,6-anhydro. Terbentuknya gel pada $\mathrm{K}$ - karagenan dan I-karagenan karena konformasi ${ }^{1} \mathrm{C}_{4}$ dari unit 3,6-anhydro-d-galactopyranosyl sehingga membentuk struktur helix ${ }^{10}$. Teori yang diterima secara luas menyatakan bahwa molekul-molekul karagenan membentuk gel melalui dua tahap. Pertama, terjadinya transisi coil-to-helix karena pengaruh temperatur dan adanya kation seperti $\mathrm{K}^{+}$atau $\mathrm{Ca}^{2+}$. Kemudian, terjadi agregasi heliks secara paralel. Ketika helix telah terbentuk, gugus sulfat terletak di luar helix (Gambar. 2) ${ }^{11}$. 


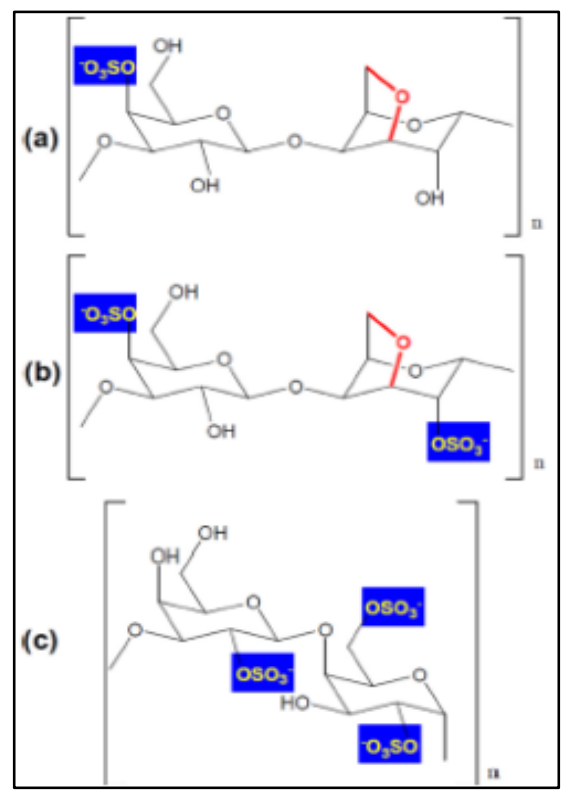

Gambar 1. Struktur dari tiga varietas utama karagenan : (a) k-karagenan; (b) Ikaragenan; (c) $\lambda$ - karagenan. Ketiga varietas dibedakan dari ada atau tidaknya jembatan 3,6-anhydro dan jumlah gugus sulfat

Di antara dua rantai terbentuk ikatan hidrogen yang bertanggungjawab terhadap kestabilan helix. $\mathrm{K}$ - karagenan dan I- karagenan dapat membentuk jaringan tiga dimensi dari kumpulan double helix. Gel yang dibentuk oleh karagenan bersifat thermoreversibel. Gel mulai terbentuk setelah pendinginan sekitar $50^{\circ} \mathrm{C}$, dan mencair ketika dipanaskan pada $80-90^{\circ} \mathrm{C}^{6}$.

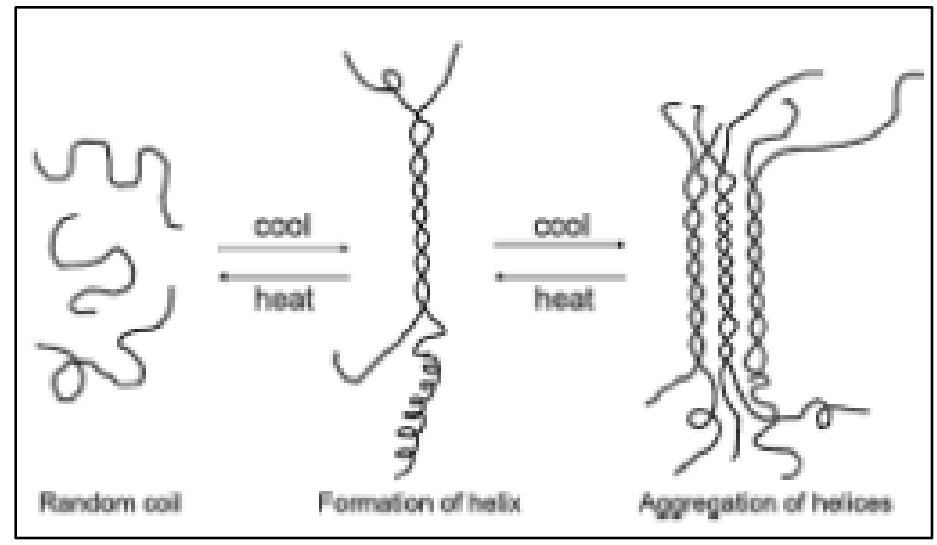

Gambar 2. Skema ilustrasi mekanisme pembentukan gel dari makromolekul karagenan

$\lambda$-karagenan yang tidak mengandung unit 3,6-anhydro-d-galactopyranosyl tidak membentuk gel. Karagenan tipe ini biasanya digunakan sebagai strongthickener ${ }^{6}$. Gugus 2-sulfat dari $\lambda$ - karagenan yang mengarah ke bagian dalam diantara dua rantai yang berdekatan mencegah terbentuknya double helix ${ }^{10}$. 


\section{Sifat Fisika Kimia Karagenan yang Dimanfaatkan di Bidang Farmasi}

Penggunaan karagenan dalam penelitian farmasetik umumnya bertujuan untuk memperbaiki formulasi obat, mengatur pelepasan obat dan menciptakan sistem penghantaran yang sensitif terhadap $\mathrm{pH} /$ temperatur sebagai respon dari lingkungan fisiologis.

\section{Matriks yang Unik untuk Memperpanjang Pelepasan Obat}

Karagenan dapat membentuk matriks bilayer yang unik dalam air yang mempengaruhi pelepasan obat. Karena adanya perbedaan hidrasi, bagian terluar tablet akan lebih dahulu mengembang dan membentuk lapisan luar yang berbentuk gel ( $\mathrm{k}$ - karagenan dan I-karagenan) dan larutan viscous ( $\lambda$ - karagenan) menyelimuti inti tablet yang belum terhidrasi ${ }^{12}$. Lapisan gel atau lapisan viscous tersebut bertindak sebagai cangkang polimer yang mengontrol disolusi dan difusi obat yang terdapat dalam tablet, dan menahan erosi tablet bahkan pada kondisi keasaman yang ekstrim ${ }^{13}$.

\section{Absoprsi Air yang Kuat untuk Meningkatkan Kelarutan Obat}

Fitur sederhana namun bermanfaat lainnya dari polimer karagenan adalah kapasitas menyerap air yang tinggi sehingga meningkatkan disolusi obat dan meningkatkan bioavailabilitas oral obat - obat yang mempunyai kelarutan yang jelek dalam air ${ }^{14}$. Karagenan menjadi alternatif praktis untuk pelet mikro-kristal selulosa (MCC) atau kapsul gelatin. Dibandingkan dengan pelet MCC yang sudah umum digunakan, pelet yang dibuat dari $\mathrm{k}$ - karagenan memungkinkan obat yang tidak larut air terdisintegrasi dan terlarut dalam 20 menit ${ }^{15,16,17 . ~}$

\section{Gugus yang Bermuatan Negatif Untuk Ikatan lon}

Fitur penting yang membuat karagenan mempunyai kapasitas yang serba guna adalah muatan negatif yang berasal dari banyaknya gugus sulfat pada struktur karagenan yang dapat mengikat molekul bermuatan positif baik molekul kecil yang akan dihantarkan atau makromolekul lain untuk membentuk sambung silang.

Ikatan ion yang terjadi antara obat dengan karagenan dapat mempermudahkan pemuatan obat (drug loading), mencegah timbulnya modifikasi atau konjugasi kovalen serta mencegah timbulnya perubahan sifat senyawa obat yang dimuatkan dalam sistem berbasis karagenan. Dalam prakteknya, sistem pengiriman obat yang dirancang dengan menggunakan basis karagenan memberikan banyak keuntungan seperti pelepasan obat diperpanjang, meningkatkan pemuatan obat dan meningkatkan disolusi obat.

Kompleks karagenan - obat yang terbentuk secara elektrostatik dapat mengontrol pelepasan obat sehingga memperbaiki bioavaiabilitas dan efek obat, meningkatkan pemuatan obat dan dapat meningkatkan kelarutan obat ${ }^{18}$.

Seperti halnya molekul kationik kecil, polimer dengan muatan positif seperti chitosan juga dapat membentuk kompleks polielektrolit dengan karagenan ${ }^{19}$. 


\section{Gugus Fungsi yang Melimpah Untuk Modifikasi Kimia dan Sambung Silang}

a. katan Crosslink Kovalen Dengan Polimer Lain Untuk Mengatur Pelepasan Obat

Karagenan (khususnya $\mathrm{k}$ - karagenan) dapat berikatan secara kovalen dengan polymer lain seperti agar-agar, polivinil alkohol atau karboksimetil selulosa, dengan bantuan dari cross linker alami genipin ${ }^{20}, 21,22,23$. Crosslinking telah terbukti meningkatkan stabilitas jaringan dan mencegah burst release ${ }^{24}$.

\section{b. Sistem Penghantaran Obat yang Sensitif Terhadap pH}

Sistem penghantaran yang sensitif terhadap $\mathrm{pH}$ sangat berguna untuk pelepasan obat pada bagian tubuh yang spesifik, seperti yang terjadi di usus. Sebagai contoh penggabungan karagenan dan chitosan dapat menghasilkan campuran polimer yang melepaskan obat pada suasana $\mathrm{pH}$ tertentu. Pada $\mathrm{pH}$ rendah, gugus sulfat dari karagenan tetap bermuatan negatif dan berinteraksi dengan gugus amino chitosan yang bermuatan positif. Sedangkan pada $\mathrm{pH} 6,8$ atau basa, gugus amino chitosan akan ternetralkan dan tidak terjadi interaksi elektrostatik. ${ }^{5}$.

Hubungan antara sifat fisika kimia karagenan dan aplikasinya di bidang farmasetik dapat digambarkan sebagai berikut :

Sifat fisika kimia

Pemanfaatan

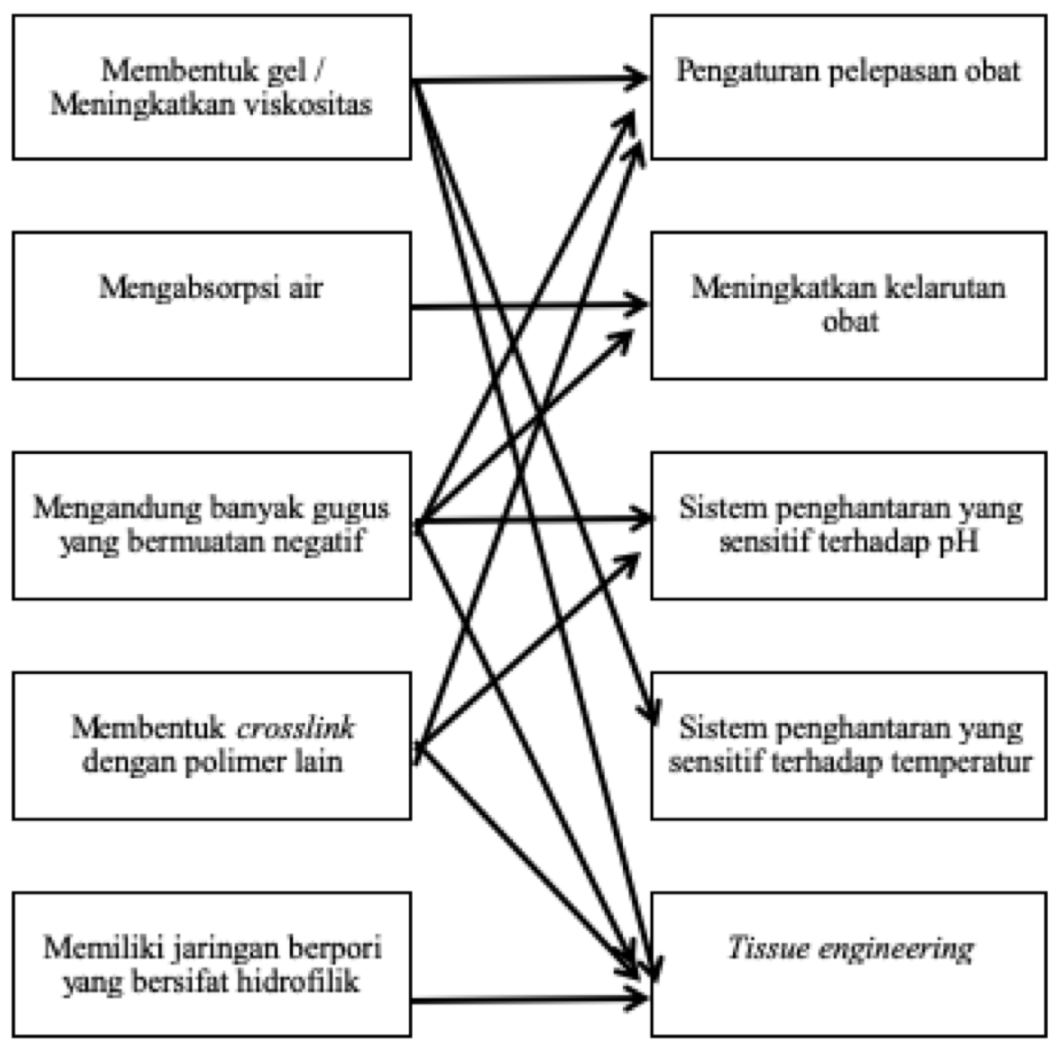

Gambar 3. Hubungan antara sifat fisikokimia karagenan dan aplikasinya di bidang farmasetik 


\section{Sistem Matriks}

Pada pembuatan tablet lepas lambat penggunaan sistem matriks sering diterapkan karena merupakan sistem yang paling sederhana. Matriks adalah zat pembawa padat yang mengatur pelepasan obat yang tersuspensi di dalamnya. Obat yang berada dalam jumlah yang lebih kecil dari matriks tersuspensi secara merata dan terlindungi dari air. Obat tersebut kemudian akan berdifusi keluar secara lambat ${ }^{25}$.

\section{Keuntungan dan Kerugian Sediaan Matriks}

Keuntungan dari sistem matriks antara lain adalah menjaga konsentrasi terapetik selama periode pengobatan yang diperpanjang, menghindari konsentrasi obat yang tinggi di dalam darah, mengurangi toksisitas dengan memperlambat absorbsi obat, meningkatkan efektifitas pengobatan, mengurangi akumulasi obat untuk obat yang ditujukan untuk penyakit kronis, dapat digunakan untuk menghantarkan senyawa dengan berat molekul yang tinggi, meningkatkan stabilitas dengan melindungi obat dari hidrolisis atau perubahan lingkungan yang ada di saluran pencernaan, mengurangi biaya pengobatan dan meningkatkan kenyamanan pasien ${ }^{26}$.

Kerugian sistem matriks antara lain adalah sisa matriks yang tersisa setelah obat dilepaskan harus dihilangkan, tergantung dari waktu tinggal sediaan dalam gastro intestinal dan meningkatnya potensial metabolisme lintas pertama ${ }^{26}$.

\section{Mekanisme Pelepasan Obat Dari Matriks Tablet}

Ketika suatu matriks hidrofilik kontak dengan air tidak terjadi proses disintegrasi melainkan hidrasi. Hal ini terjadi karena polimer penyusun matriks hidrofilik mempunyai sifat dapat membentuk gel. Proses hidrasi ini berkaitan dengan meningkatnya ukuran molekul polimer sebagai konsekuensi dari masuknya cairan ke dalam sistem matriks. Selanjutnya di lapisan terluar matriks terbentuk suatu daerah dimana polimer mengalami transisi dari fasa kristalin menjadi rubbery state atau dikenal sebagai lapisan gel ${ }^{27}$. Cairan selanjutnya terus berpenetrasi memasuki lapisan gel dan inti tablet yang belum terbasahi. Semakin banyak air yang memasuki sistem matriks maka semakin tebal lapisan gel yang terbentuk. Pada saat yang bersamaan hampir seluruh rantai polimer yang telah terbasahi secara bertahap mengalami relaksasi sampai hilang konsistensinya dan terjadilah erosi matriks pada tablet ${ }^{28}$.

Penetrasi medium ke dalam matriks menimbulkan beberapa lapisan, dimana lapisan lapisan tersebut akan menghilang sepanjang proses disolusi matriks ${ }^{27}$ :

\section{a. Lapisan Tempat Terjadinya Pengembangan (The Swelling Front)}

Dengan masuknya air ke dalam matriks, polimer mengalami transisi dari bentuk kristalin menjadi bentuk terhidrasi atau bentuk gel (rubbery region). Lapisan ini memisahkan bagian kristain dari bagian yang sudah menjadi gel. 


\section{b. Lapisan Tempat Terjadinya Erosi (The Erosion Front atau Dissolution Front)}

Lapisan ini memisahkan daerah yang sudah menjadi gel dengan media disolusi. Pada lapisan ini rantai polimer yang telah terbasahi secara bertahap mengalami relaksasi sampai hilang konsistensinya dan terjadilah erosi matriks.

\section{c. Lapisan Tempat Terjadinya Difusi ( Diffusion Front)}

Lapisan ini berada di antara the swelling front dan the dissolution front dan memisahkan daerah matriks yang telah menjadi gel yang mengandung obat yang sudah terlarut dalam medium dengan daerah matriks yang mengandung obat yang belum terlarut. ${ }^{29}$

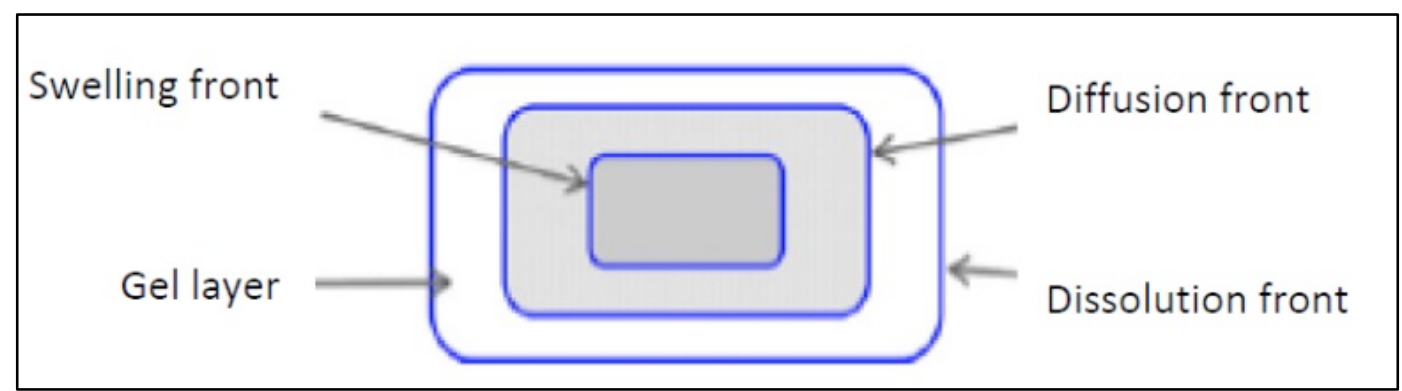

Gambar 4. Skema matriks hidrofilik setelah masuknya cairan medium disolusi ke dalam matriks

\section{Pengaturan Pelepasan Obat dari Matriks Karagenan}

Sistem matriks hidrofilik merupakan sistem penghantaran obat yang paling sering digunakan untuk mengatur pelepasan obat. Karagenan dapat digunakan sebagai penyusun matriks mengingat polimer tersebut memiliki berat molekul yang besar dan mempunyai viskositas dan kemampuan membentuk gel yang tinggi.

\section{Sebagai Matriks Tunggal Pada Tablet Extended Release}

Karagenan dapat digunakan sebagai matriks tablet walaupun dengan kapasitas loading obat yang terbatas. Sebagai contoh telah diteliti penggunaan $\mathrm{I}-$ karagenan dan $\lambda-$ karagenan sebagai matriks pada pembuatan tablet tripelennamin $\mathrm{HCl}$ sebagai senyawa model. Dengan menggunakan campuran $\mathrm{I}$ - karagenan dan $\lambda$ - karagenan sama banyak dan drug loading $10 \%$ diperoleh pengaturan pelepasan obat hampir mendekati orde nol. Namun ketika drug loading ditingkatkan menjadi $30 \%$, tablet pecah selama proses disolusi dan pengaturan pelepasan mendekati orde nol tidak tercapai ${ }^{30}$.

Telah diteliti penggunaan $\mathrm{k}$ - karagenan sebagai matriks dan mikrokristalin selulosa sebagai pengisi pada pembuatan tablet teofilin monohidrat dengan drug loading $20 \%$. Pada konsentrasi karagenan $20 \%$ pelepasan teofilin monohidrat lebih cepat dari konsentrasi karagenan $30 \%$ dan pada konsentrasi karagenan $70 \%$ diperoleh pengaturan pelepasan mengikuti kinetika orde nol ${ }^{31}$. 
Penelitian lain dengan menggunakan $\mathrm{K}$ - karagenan sebagai matriks pada pembuatan tablet teofilin kempa langsung dengan drug loading 10\% telah dilakukan. Pada konsentrasi karagenan $10 \%$ dapat diketahui bahwa jenis bahan pengisi tablet yang digunakan berpengaruh besar terhadap kecepatan pelepasan obat. Pengisi laktosa memberikan kecepatan pelepasan obat yang lebih besar dibandingkan dengan dibasic calcium phosphate dan mikrokristalin selulosa. Media disolusi yang digunakan juga dapat mempengaruhi pelepasan obat. Pelepasan obat pada $\mathrm{pH} 7,4>0,1 \mathrm{~N} \mathrm{HCl}>$ akuadest. Pengaturan pelepasan obat dapat dilakukan ketika konsentrasi karagenan yang digunakan $30-40 \%{ }^{32}$.

Tingkat kecepatan rotasi alat disolusi juga mempengaruhi kecepatan pelepasan obat. Semakin cepat rotasi alat disolusi akan menurunkan integritas lapisan gel dan mempercepat pelepasan obat. Penambahan kation monovalen atau divalen seperti kalium atau kalsium klorida juga dapat mempengaruhi kemampuan mengembang $\mathrm{k}$ dan I karagenan tergantung konsentrasi kation dan tipe obat yang digunakan ${ }^{33}$.

\section{Campuran Polimer Sebagai Matriks Pada Tablet Extended Release}

Penggunaan karagenan sebagai matriks tunggal untuk mengatur pelepasan obat seringkali tidak memberikan hasil yang memuaskan seperti tidak diperolehnya pelepasan obat pada orde nol dan terdegradasinya matriks karena pengaruh $\mathrm{pH}$. Untuk mendapatkan pengaturan pelepasan obat yang diinginkan dapat digunakan campuran polimer karagenan dan polimer lain sebagai penyusun matriks tablet ${ }^{27}$.

Dilaporkan oleh Bonferoni et. al bahwa erosi tablet dengan matriks $\lambda$ - karagenan dipengaruhi $\mathrm{pH}$ dari media disolusi. Penambahan hidroksi propil metil selulosa yang mengalami erosi lebih lambat dibandingkan dengan karagenan pada matriks dapat memperlambat pelepasan obat pada berbagai $\mathrm{pH}$ media disolusi. Kemudian dengan rasio HPMC dan karagenan yang optimal diperoleh pelepasan klorfeniramini maleat dari tablet yang linier dan bertahan sampai 24 jam $^{34}$.

Dilaporkan oleh Nerurkar, Jun, Price \& Park bahwa tablet ibuprofen kempa langsung dengan sistem matriks yang terdiri dari campuran polimer $\mathrm{I}, \boldsymbol{\lambda}-\mathrm{k}$ karagenan dan turunan selulosa (HPMC, Na CMC, MC, HPC) memberikan profil pelepasan yang linier dan pelepasan ibuprofen diperpanjang $12-16$ jam $^{4}$.

Penelitian juga telah dilakukan terhadap campuran matriks chitosan dan karagenan dengan harapan memperoleh pengaturan pelepasan obat yang diperpanjang. Karagenan yang bermuatan negatif secara spontan akan berinteraksi dengan polyion bermuatan positif seperti chitosan dan memmbentuk kompleks polielektrolit. Akan tetapi karena kapasitas menyerap air yang tinggi dari karagenan menyebabkan disintegrasi tablet yang prematur dan matriks tidak mengembang ${ }^{14}$. Ketika tablet dipindahkan ke dalam media simulasi usus terjadi lapisan film polielektrolit in situ yang dapat mengatur pelepasan obat. Campuran chitosan dan $\lambda$ - karagenan merupakan kandidat matriks dengan pengaturan pelepasan obat yang cukup menjanjikan karena sensitivitas terhadap $\mathrm{pH}$ dan kekuatan ion yang lebih rendah dibandingkan dengan campuran matriks chitosan $\mathrm{K}$ - karagenan dan chitosan $\mathrm{I}$ - karagenan ${ }^{8}$. 


\section{Karagenan Sebagai Eksipien untuk Mengatur Pelepasan Obat yang Bersifat Basa}

Struktur karagenan yang mengandung ester sulfat dapat bereaksi dengan senyawa yang bermuatan positif ${ }^{35}$. Penelitian menunjukkan karagenan berinteraksi dengan beberapa obat yang bersifat basa sehingga dapat mengatur pelepasan awal dari obat dan menekan burst release ${ }^{36}$.

Salbutamol sulfat yang bersifat basa dapat membentuk interaksi ionik obat - polimer dengan $\lambda$ - karagenan yang mempengaruhi pelepasannya dari tablet. Dalam hal ini dipengaruhi juga oleh media disolusi yang digunakan (aquadest, $\mathrm{pH} 1,2$ dan $\mathrm{pH} 6,8)^{35}$. Karagenan tipe $\lambda$ dengan kadar $40 \%$ dari campuran matriks $\lambda$ - karagenan - HPMC memberikan pengaturan pelepasan salbutamol sulfat dan klorfeniramin maleat yang baik, dengan profil pelepasan mendekati linier ${ }^{34}$. Mekanisme pengaturan pelepasan ini berdasarkan terjadinya interaksi yang tidak spesifik antara obat yang bersifat basa dan $\lambda$ - karagenan ketika tablet kontak dengan media disolusi. Interaksi ini menurunkan difusi obat sehingga pelepasan obat lebih banyak diatur oleh erosi pembawa ${ }^{37}$. Kombinasi dari berbagai mekanisme seperti water uptake, erosi dan interaksi polimer dengan obat dapat menghasilkan pengaturan pelepasan obat lebih dari 24 jam ${ }^{9,12}$.

\section{Kesimpulan}

Aplikasi karagenan di bidang farmasetika meningkat pesat dalam dekade terakhir ini. Penggunaan karagenan dalam matriks tablet merupakan salah satu subjek penelitian yang menarik untuk dilakukan. Sifat fisika kimia karagenan seperti kemampuan membentuk gel, muatan negatif yang kuat dan viskositasnya yang tinggi telah banyak diteliti sebagai pengatur pelepasan obat. Mengingat ada 3 tipe utama karagenan $(\lambda$, I dan $\mathrm{k}$ ) yang berbeda sifatnya, perlu dilakukan eksplorasi untuk menentukan tipe karagenan yang sesuai dengan sistem penghantaran dan obat yang digunakan.

Perlu dilakukan analisis lebih lanjut mengenai mekanisme penghantaran obat dengan menggunakan karagenan karena informasi yang telah diperoleh belum cukup lengkap. Saat ini penelitian yang telah dilakukan fokusnya masih terbatas pelepasan obat secara in vitro. Korelasi antara hasil penelitian in vitro dan in vivo perlu dilakukan di masa yang akan datang.

\section{Daftar Pustaka}

1. Van de Velde, F., Knutsen, S. H., Usov, A. I., Rollema, H. S., \& Cerezo, A. S. 2002.1H and13C high resolution NMR spectroscopy of carrageenans: Application in research and industry. Trends in Food Science \& Technology, 13(3), 73-92.

2. K.M. Picker. 1999. The use of carrageenan in mixture with microcrystalline cellulose and its functionality for making tablets. Eur. J. Pharm. Biopharm. $4827-36$.

3. Liang, W., Mao, X., Peng, X., \& Tang, S. 2014. Effects of sulfate group in red seaweed polysaccharides on anticoagulant activity and cytotoxicity. Carbohydrate Polymers, 101, 776-785. 
4. Nerurkar, J., Jun, H. W., Price, J. C., \& Park, M. O. 2005. Controlled-release matrix tablets of ibuprofen using cellulose ethers and carrageenans: Effect of formulation factors on dissolution rates. European Journal of Pharmaceutics and Biopharmaceutics, 61, 56-68.

5. Li, L., Ni, R., Shao, Y., \& Mao, S. 2014. Carrageenan and its applications in drug delivery. Carbohydrate Polymers, 103C, 1-11.

6. Bixler, H. J. 1994. The carrageenan connection IV. British Food Journal, 96(3), 1217.

7. Necas, J., \& Bartosikova, L. 2013. Carrageenan: A review. Veterinarni Medicina, 58(4),187-205.

8. Li, L., Wang, L., Shao, Y., Tian, Y., Li, C., Li, Y., et al. 2013. Elucidation of release characteristics of highly soluble drug trimetazidine hydrochloride from chitosancarrageenan matrix tablets. Journal of Pharmaceutical Sciences, 102(8),2644-2654.

9. Pavli, M., Vrecer, F., \& Baumgartner, S. 2010. Matrix tablets based on carrageenans with dual controlled release of doxazosin mesylate. International Journal of Pharmaceutics, 400(1-2), 15-23.

10. Campo, V. L., Kawano, D. F., Silva, D. B. d., \& Carvalho, I. 2009. Carrageenans: Bio-logical properties, chemical modifications and structural analysis-A review.Carbohydrate Polymers, 77(2), 167-180.

11. Yuguchi, Y., Urakawa, H., \& Kajiwara, K. 2003. Structural characteristics of carrageenan gels: Various types of counter ions. Food Hydrocolloids, 17(4), 481485 .

12.Pavli, M., Baumgartner, S., Kos, P., \& Kogej, K. 2011. Doxazosin-carrageenan interac-tions: A novel approach for studying drug-polymer interactions and relation to controlled drug release. International Journal of Pharmaceutics, 421(1), 110-119.

13. Miyazaki, S., Ishitani, M., Takahashi, A., Shimoyama, T., Itoh, K., \& Attwood, D. 2011. Carrageenan gels for oral sustained delivery of acetaminophen to dysphagic patients. Biological and Pharmaceutical Bulletin, 34(1), 164-166.

14. Tapia, C., Escobar, Z., Costa, E., Sapag-Hagar, J., Valenzuela, F., Basualto, C., et al. 2004. Comparative studies on polyelectrolyte complexes and mixtures ofchitosan-alginate and chitosan-carrageenan as prolonged diltiazem clorhydrate release systems. European Journal of Pharmaceutics and Biopharmaceutics,57(1), $65-75$.

15. Ghanam, D., \& Kleinebudde, P. 2011. Suitability of kappa-carrageenan pellets forthe formulation of multiparticulate tablets with modified release. International Journal of Pharmaceutics, 409(1-2), 9-18. 
16. Kranz, H., Juergens, K., Pinier, M., \& Siepmann, J. 2009. Drug release from MCCandcarrageenan-based pellets: Experiment and theory. European Journal of Pharma-ceutics and Biopharmaceutics, 73, 302-309.

17. Thommes, M., \& Kleinebudde, P. 2006a. Use of kappa-carrageenan as alternative pelletisation aid to microcrystalline cellulose in extrusion/spheronisation.I. Influence of type and fraction of filler. European Journal of Pharmaceutics and Biopharmaceutics, 63, 59-67.

18. J. Liu et.al. 2015. Review for Carrageenan-Based Pharmaceutical Biomaterials : Favourable Physical Features Versus Adverse Biological Effects. Carbohydrate Polimer 121, 27-36.

19. Briones, A. V., \& Sato, T. 2010. Encapsulation of glucose oxidase (GOD) in polyelectrolyte complexes of chitosan-carrageenan. Reactive and Functional Polymers,70(1), 19-27.

20. Hezaveh, H., \& Muhamad, I. I. 2012. The effect of nanoparticles on gastrointestinalrelease from modified - carrageenan nanocomposite hydrogels. Carbohydrate Polymers, 89(1), 138-145.

21. Hezaveh, H., \& Muhamad, I. I. 2013a. Controlled drug release via minimization ofburst release in $\mathrm{pH}$-response kappa-carrageenan/polyvinyl alcohol hydrogels. Chemical Engineering Research and Design, 91(3), 508-519.

22. Hezaveh, H., \& Muhamad, I. I. 2013b. Modification and swelling kinetic study of kappa-carrageenan-based hydrogel for controlled release study. Journal of the Taiwan Institute of Chemical Engineers, 44(2), 182-191.

23. Hezaveh, H., Muhamad, I. I., Noshadi, I., Shu Fen, L., \& Ngadi, N. 2012. Swelling behaviour and controlled drug release from cross-linkedcarrageenan/NaCMChydrogel by diffusion mechanism. Journal of Microencapsulation, 29(4), 368-379.

24. Kulkarni, R. V., Boppana, R., Krishna Mohan, G., Mutalik, S., \& Kalyane, N. V. 2012. pH-responsive interpenetrating network hydrogel beads of poly(acrylamide)-gcarrageenan and sodium alginate for intestinal targeted drug delivery:Synthesis, in vitro and in vivo evaluation. Journal of Colloid and Interface Science,367(1), 509517.

25. Shargel, L. dan Yu. 2005. Biofarmasetika dan Farmakokinetika Terapan. Edisi Kedua. Surabaya: Airlangga University Press.

26. Manish J. Chauhan, Satish A. Patel. 2012. A concise review on sustained drug delivery system and it's opportunities. American Journal of PharmTech Research 2012; 2(2) .2249-3387. 
27. Maderuelo, C., Zarzuelo, A., \& Lanao, J. M. 2011. Critical factors in the release ofdrugs from sustained release hydrophilic matrices. Journal of Controlled Release,154, 2-19.

28. Ju, R.T.C., Nixon, P.R., Patel, M.V.1995. Drug release from hydrophilic matrices. 1. New scaling laws for predicting polymer and drug release based on the polymer disentanglement concentration and the diffusion layer. J. Pharm. Sci. 84, 1455-1463.

29. Bettini, R., Catellani, P.L., Santi, P., Massimo, G., Peppas, N.A., Colombo, P. 2001. Translocation of drug particles in HPMC matrix gel layer : effect of drug solubility and influence on release rate. J. Control. Rel. 70, 383-391.

30. Hariharan, M., Wheatley, T. A., \& Price, J. C. 1997. Controlled-release tablet matrices from carrageenans: Compression and dissolution studies. Pharmaceutical Development and Technology, 2, 383-393.

31. Picker, K. M. 1999a. The use of carrageenan in mixture with microcrystalline cellulose and its functionality for making tablets. European Journal of Pharmaceuticsand Biopharmaceutics, 48, 27-36.

32. Rosario, N. L., \& Ghaly, E. S. 2002. Matrices of water-soluble drug using natural poly-mer and direct compression method. Drug Development and Industrial Pharmacy,28, 975-988.

33. Picker, K. M. 1999b. Matrix tablets of carrageenans. II. Release behavior and effectof added cations. Drug Development and Industrial Pharmacy, 25, 339-346.

34. Bonferoni, M. C., Rossi, S., Tamayo, M., Pedraz, J. L., Dominguez-Gil, A., \& Caramella,C. 1994. On the employment of $\lambda$-carrageenan in a matrix system. II. $\lambda$ Carrageenan and hydroxypropylmethylcellulose mixtures. Journal of Controlled Release, 30, 175-182.

35. Moreno-Villoslada, I., Oyarzun, F., Miranda, V., Hess, S., \& Rivas, B. L. 2005. Binding of chlorpheniramine maleate to pharmacologically important alginic acid,carboxymethylcellulose, kappa-carageenan, and iota-carrageenan as studied by diafiltration. Journal of Applied Polymer Science, 98, 598-602.

36. Kojima, H., Yoshihara, K., Sawada, T., Kondo, H., \& Sako, K. 2008. Extended release of a large amount of highly water-soluble diltiazem hydrochloride by utilizing counter polymer in polyethylene oxides (PEO)/polyethylene glycol (PEG)matrix tablets. European Journal of Pharmaceutics and Biopharmaceutics, 70,556-562.

37. Bonferoni, M. C., Rossi, S., Tamayo, M., Pedraz, J. L., Dominguez-Gil, A., \& Caramella, C. 1993. On the employment of $\lambda$-carrageenan in a matrix system. I. Sensitivity to dissolution medium and comparison with $\mathrm{Na}$ carboxymethylcellulose and xanthan gum. Journal of Controlled Release, 26, 119-127. 
38. Bonferoni, M. C., Chetoni, P., Giunchedi, P., Rossi, S., Ferrari, F., Burgalassi, S., et al. 2004. Carrageenan-gelatin mucoadhesive systems for ion-exchange based ophthalmic delivery: In vitro and preliminary in vivo studies. European Journal of Pharmaceutics and Biopharmaceutics, 57, 465-472. 